\title{
Study on Medicinal Plants of Kashmir Valley for Anti-Proliferative, Anti-Invasive Activities against Prostate Cancer
}

\author{
Wasia Showkat ${ }^{1}$, F.A. Nehvi ${ }^{2}$, Zahoor A. Dar ${ }^{3}$, Javeed A. Mugloo ${ }^{4}$, Niyaz A. Dar ${ }^{1}$, \\ Shakeel A. Mir ${ }^{5}$, M. Ashraf Bhat ${ }^{6}$ and Khalid Z. Masoodi ${ }^{{ }^{*}}$
}

\author{
${ }^{1}$ Transcriptomics Laboratory, Division of Plant Biotechnology, ${ }^{2}$ Division of Plant \\ Biotechnology, SKUAST-K, Shalimar, Srinagar, J\&K, India, 190025 \\ ${ }^{3}$ Department of Biotechnology, Kashmir University, Hazratbal, Srinagar, India \\ ${ }^{4}$ Faculty of Forestry, SKUAST-K, Benihama, Ganderbal, India \\ ${ }^{5}$ Division of Agricultural Statistics, SKUAST-K, Shalimar, India \\ ${ }^{6}$ Genetics and Plant Breeding, FoA, Wadura, SKUAST-K, India
}

*Corresponding author

\section{Keywords}

Kashmir

Himalayas,

Medicinal plants,

Prostate cancer,

Colony forming

unit assay, Wound

healing assay

Article Info

Accepted:

04 May 2019

Available Online:

10 June 2019

\section{A B S T R A C T}

Treatment of castration-resistant prostate cancer (CRPC) patients with androgen deprivation therapy puts prostate cancer in remission while treatment with already available drugs in market including abiraterone help in controlling advanced prostate cancers for sometime though fail to respond, evolve resistance mechanisms, and undergo genetic deregulations later on with poor patient survival rate and no cure. Also, if present trends of increasing life expectancy continue, given the current age-specific incidence, mortality rates of prostate cancer, this disease will become a far greater health problem worldwide in future. For this reason, addressing the curative treatment strategies for prostate cancer was the focal theme of our investigation. Our emphasis was on the extracts from medicinal plants of Kashmir Valley, which we collected from different floristically rich regions of Valley including Leh-Ladakh, Gurez, Dachigam National Sanctuary, Jawahar Lal Nehru Memorial Botanical Garden, Medicinal Plants Emporium Srinagar, Faculty of Forestry, SKUAST-K, Kangan and local nurseries in Srinagar area. In this study, we screened library of 372 extracts from collected medicinal plants (52) for their antiproliferative and anti-invasive efficacy through colony forming units and wound healing assays, which led to the identification of leaf extract of Podophyllum hexandrum as inhibitor molecule.Wound healing assay revealed that in presence of this extract, cancer cells show inhibition of cell migration, thus showing detrimental effect on invasiveness of C4-2 cells. CFU assay depicted inhibition of cellular proliferation and reduced colony forming units in $\mathrm{C} 4-2, \mathrm{LnCaP}$ and $\mathrm{PC} 3$ cells with increasing concentrations of this extract. Potential of this extract as a lead compound for the development of new treatment options for CRPC, including those resistant to enzalutamide, abiraterone and other anti-androgens could be explored through future studies. Also, different extracts of this plant will act as tool for evaluation of wide range of biological activities. 


\section{Introduction}

Utilization of plants for medicinal purposes dates back to centuries, even before long recorded history(Jamshidi-Kia, Lorigooini et al., 2018). Primitive men valued, appreciated the great diversity and helpfulness of plants accessible to them( $\mathrm{Li}$ and $\mathrm{Lou} 2018)$. As times passed by, each tribe added the medicinal power of herbs in their field to its knowledge base(Dereli, Ilhan et al., 2019).Treatment of number of diseases including diabetes with plant-derived drugs are the earliest success stories(Jacob, Li et al., 2019). Today, we are more concerned with the life-style diseases like cancer (Zhong, Pascal et al., 2018). With cancer being a boundless risk to the mankind, plants in the form of useful products can assume a significant job in cancer counteractive action, as well as in its therapy(Jing, Nguyen et al., 2018). Globally cancer is a disease that seriously effects the human population and as a consequence there is a consistent interest for development of new treatments to prevent this perilous disease(Masoodi, Xu et al., 2017). Scientific and research intrigue is constantly drawing its consideration towards naturallyderived compounds(Isgut, Rao et al., 2018) as they are considered to have less toxic side effects contrasted with current modes of treatment using allopathy as well as chemical induced processes such as chemotherapy (Seca and Pinto 2018). Plants therefore, have been indispensable in treating diverse forms of diseases including cancer (Buyel 2018).

In recent years, medicinal plants have occupied an important position in being the paramount sources of drug discovery, irrespective of their categorized groups- herb, shrub or tree (Tewari, Rawat et al., 2019). These practices have solely been based on the knowledge of traditional use of medicinal plants(Kaushik and Kaushik 2018). Proper understanding of the complex synergistic interaction of various constituents of anticancer herbs(Agyare, Spiegler et al., 2018), should therefore, help in formulating the treatment design to attack the cancerous cells without harming the normal cells of the body(Bhat, Gul et al., 2018).The Plant kingdom produces naturally occurring secondary metabolites that are being investigated for their anticancer activities leading to the development of new clinical drugs(Ullah and Ahmad 2019). With the success of these compounds that have been developed into staple drugs for cancer treatment, new technologies are emerging to develop the area further(Rupani and Chavez 2018). Thus, there is lately a great deal of interest in screening plants to be eventually used in cancer prevention and treatment.

Among different types of cancers, prostate cancer is one of the chief reasons for mortalities in men worldwide(1,276,106 number of new cases $[7.1 \%$ of total cases of cancer], 358,989 number of death [3.8\% of total cancer deaths]as of 2018)(Keavey and Thompson 2018)and medical castration is the standard-care treatment for the patients (AwYong, Gan et al., 2018). Aggressive prostate cancers have a progressive and morbid disease process with a median survival of 930 months(Johnston, Nguyen et al., 2016). Androgen-deprivation therapy puts prostate cancer in remission(Eisermann, Dar et al., 2015), whereas hormonal therapies help in controlling advanced prostate cancers for sometime though fail to respond (Khan and Gurav 2018), evolve resistance mechanisms, and undergo genetic deregulations later on with poor patient survival rate and no cure(Wang, Nguyen et al., 2015). If the present trends of increasing life expectancy continue, given the current age-specific incidence, morbidity and mortality rates of prostate cancer(Kebebe, Liu et al., 2018), this disease will become a far greater health problem worldwide in future(Pascal, Masoodi et al., 2015). 
For this reason, addressing the curative treatment strategies of prostate cancer was the focal theme of our investigation. And for the same, we screened library of 372 plant extracts for their capability to inhibit colony forming units and cell migration/movement of castration resistant prostate cancer cells, which led to the identification of leaf extract of Podophyllum hexandrum as inhibitory extract in both the assays.

\section{Materials and Methods}

\section{Plant material}

52 medicinal plants both fresh as well as dried (leaves, roots, flowers, seeds, fruit, bark and other parts) were collected in different seasons (flowering as well as fruiting), from different regions of Kashmir Valley (including Leh-Ladakh, Gurez, Jawahar Lal Nehru Memorial Botanical Garden Srinagar, Medicinal Plants Emporium Srinagar, Faculty of Forestry, Benihama) during 2016-2017 (Figure 1a-1e). Voucher specimens were deposited at the SKUAST-K herbarium. Fresh plant parts were washed thoroughly with tap water, shade dried, homogenized to fine powder and stored in airtight bottles/ ziplocks. Dried plant parts were also subjected to grinding and stored in airtight ziplocks. Plants used for investigation of anticancer activity were subjected to following methods:

\section{Preparation of extracts}

For preparation of extracts, 20-25gms of powder of each plant part was subjected to soxhlet extraction with different solvents for $48 \mathrm{hrs}$. For each plant part, six extracts were obtained. The extracts were dried using rotary vacuum evaporator, dissolved in $10 \mathrm{ml}$ DMSO, filter sterilized, weighed and stored in $-20^{\circ} \mathrm{C}$ until tested. The extracts were formatted at $12.5 \mathrm{mg} / \mathrm{ml}$ concentration, from which further dilutions were made in RPMI1640 medium at the time of testing.

\section{Reagents}

Dimethyl sulfoxide (DMSO), phosphatebuffered saline (PBS) (Cat no. TL1031), Cyclohexane, Hexane, Diethyl ether, Ethyl acetate, Methanol were obtained from Himedia. RPMI-1640 medium (Cat no.11875093), L-glutamine (Cat no.25030081) ,fetal bovine serum (FBS), trypsin (Cat no. 25200056) were obtained from Gibco/Life Technology .

\section{Cell culture establishment}

C4-2 cells were obtained from Zhou Wang's Laboratory, University of Pittsburgh, under MTA with MD Anderson Cancer Centre Texas USA and LnCaP, and PC3 cells were obtained from NCCS Pune. Cell lines were maintained in the RPMI-1640 medium supplemented with $10 \%$ FBS, $1 \%$ Pennstrep and $1 \%$ L-glutamine at $37^{\circ} \mathrm{C}$ with $5 \% \mathrm{CO}_{2}$ (Figure 2).

\section{Colony forming Unit Assay (CFU)}

The colony forming unit assay was utilized to determine the effect of extract library on the cell regrowth of prostate cancer cells.

All the three cell lines (C4-2, LnCap, PC3) were seeded in 12 well plates prior to treatment with extracts. Cell lines at $70-90 \%$ confluency was washed with PBS and treated with different concentrations of plant extracts $(3.12,6.25,12.5,25$ and $50 \mu \mathrm{g} / \mathrm{ml})$, DMSO control and incubated for $48 \mathrm{hrs}$. Then an equal number of cells from treated wells were seeded in $10 \mathrm{~cm}$ dishes to form colonies for atleast 7 to 10 days. After removing the media gently from the dishes, sufficient $100 \%$ methanol to cover the cells completely was added to plates, which were then incubated for 20 mins. The methanol was removed and cells rinsed carefully with water. Sufficient crystal violet solution was added to cover the cells and incubated for 5 mins. at room 
temperature. The cells were washed with water to remove excess dye. Then the plates were kept inverted on tissue paper to dry overnight. The colonies were counted using ImageJ software. Data was analysed using Graph Pad Prism 7.0.

\section{Cell Migration Assay using Wound Healing}

C4-2 cells were grown in 24-well plates to $70-80 \%$ confluency. Nextday, media was removed from plates and the monolayer was gently scratched with a sterile $200 \mu$ pipette tip across the center of the well (straight scratches were made). While scratching across the surface of the well, care was taken to keep the long-axial of the tip perpendicular to the bottom of the well. After scratching, wells were washed with PBS to remove the detached cells and the wells were filled with fresh RPMI media supplemented with $10 \%$ FBS, 1\% L-glutamine, 1\% Pennstrep. Images of the cellular gap were captured in bright field on LMI inverted microscope before the addition of plant extracts. The cells were then treated with plant extracts at a concentration of $50 \mu \mathrm{g} / \mathrm{ml}$ and wells treated with vehicle DMSO was used as control. After addition of plant extracts, the well plates were incubated at $5 \% \quad \mathrm{CO}_{2}$ and $37^{\circ} \mathrm{C}$, while capturing the images of the cellular gap periodically at $0 \mathrm{hrs}$ and $48 \mathrm{hr}$ timings in bright field on LMI inverted microscope to note down the changes in the gap distance of scratch. The cellular gap distance was quantitatively evaluated as percentage wound area using Graph pad Prism 7.0

\section{Statistical analysis}

For statistical analysis and graphical composition, GraphPad Prism 7.0 (GraphPad Software, Inc) and MS Excel 2003 (Microsoft) were used. Data was expressed as the mean \pm SEM and to determine statistical significance, one-way ANOVA or Student's t-test was used.

\section{Results and Discussion}

\section{Library construction of the extracts from the collected medicinal plants}

Crude extract library comprising 372 plant extracts was formed during the investigation (Table 1).We gave our own set of nomenclature to constructed library, according to which the first part of the drug name i.e. 1,2,3, and so represents the sequential location/position of extract in the library. The second part of the drug name is the first letter of the plant part/organ name, that is used in the extract preparation, followed by the third part of the drug name including the first two letters (first letter of generic name and first letter of species name) of the botanical name of the source plant. The last part of the name represents the solvent system, used for extract preparation. Different parts of the drug name are separated from each other by a hyphen. The crude extracts of this library, both serving as drugs and as templates for the synthesis of drugs will serve many researchers and drug companies to facilitate drug discovery as a tool for the evaluation of a wide range of biological activities.

\section{Colony Forming Unit Assay}

Podophyllum hexandrum leaf extract inhibited colony forming unit ability of all three cell lines with increasing concentrations (Figure 3).At lower concentrations, there was reduction in number of colonies when compared to control while at higher concentrations the plates were empty with no colonies suggesting the inhibition of colony forming units takes place in a concentration dependent manner (Figure 3).

\section{Cell migration using wound healing assay}

Podophyllum hexandrum leaf extract signifi- 
cantly inhibited cancer cell migration in timedependent manner (Figure4). Extract inhibited C4-2 cancer cell migration by $70 \%$ at a concentration of $50 \mu \mathrm{g} / \mathrm{ml}$, in comparison with the untreated control group (Figure
4).There was no significant gap closure in wells treated with Podophyllum hexandrum leaf extract while there was near $40 \%$ gap closure in control plate.

Table.1 Library construction of the isolated extracts from collected medicinal plants

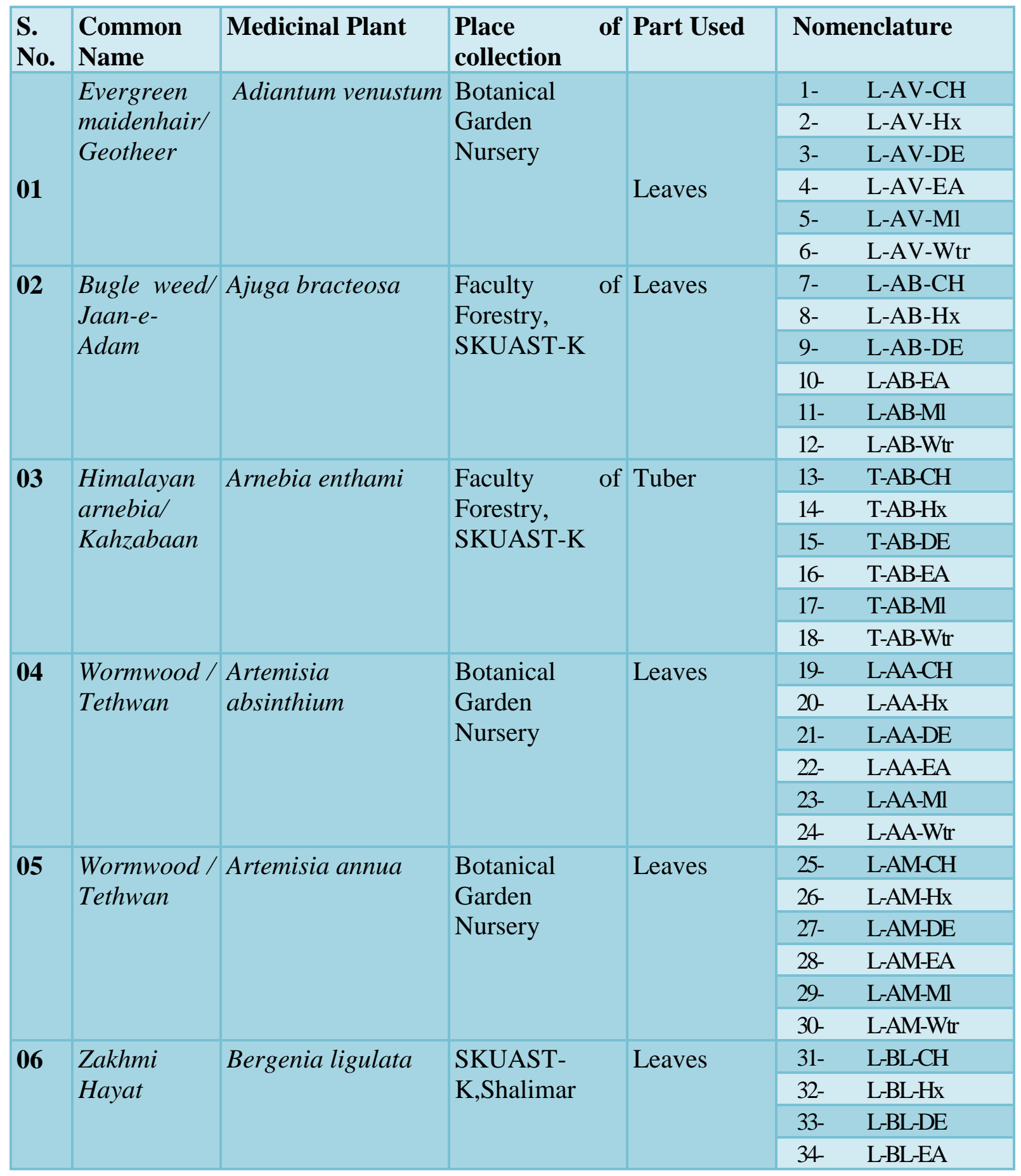




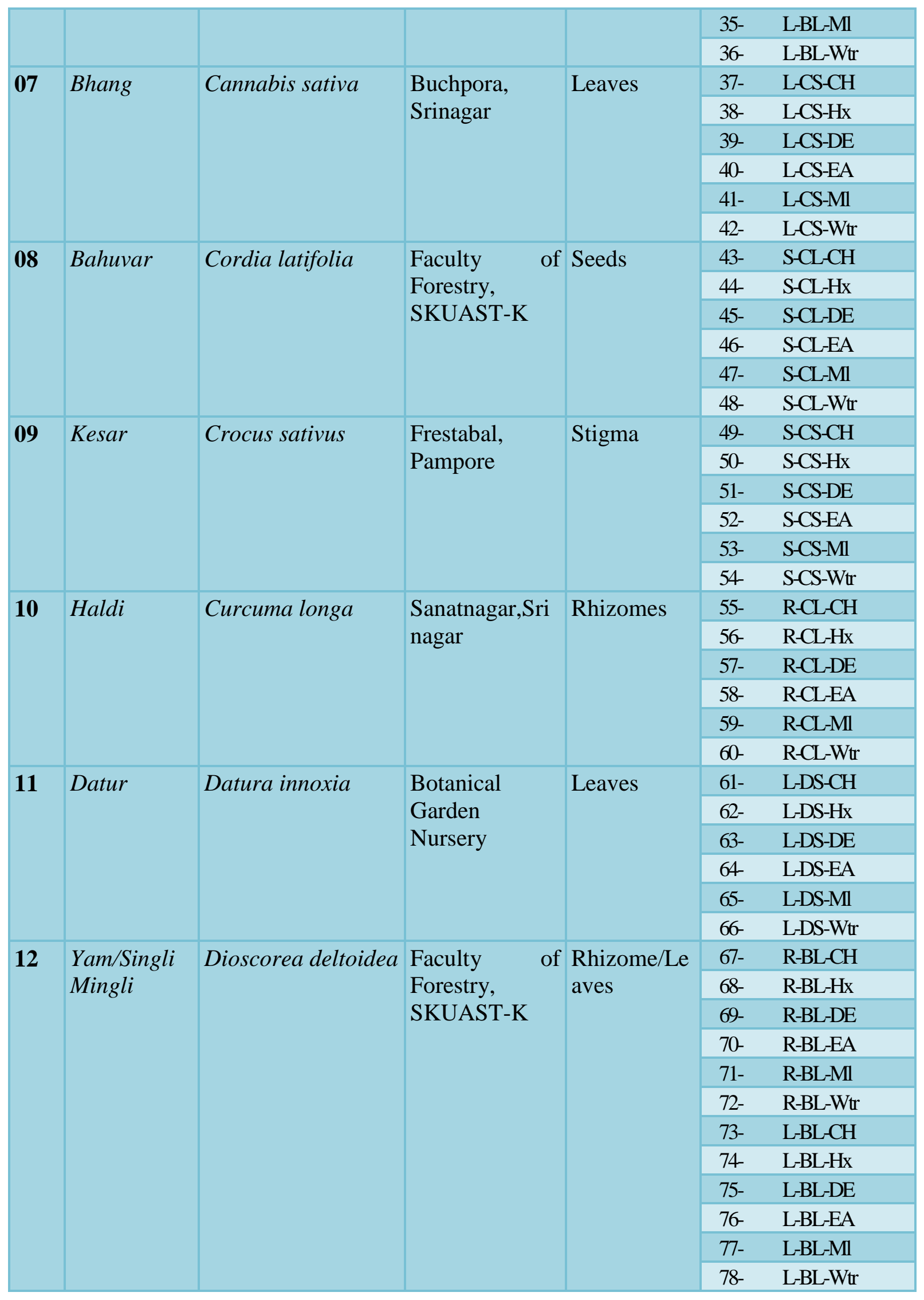




\begin{tabular}{|c|c|c|c|c|c|c|}
\hline \multirow[t]{6}{*}{13} & \multirow{6}{*}{ Yam } & \multirow{6}{*}{$\begin{array}{l}\text { Dioscorea } \\
\text { balcanica }\end{array}$} & \multirow{6}{*}{$\begin{array}{l}\text { Faculty of } \\
\text { Forestry, } \\
\text { SKUAST-K }\end{array}$} & \multirow{6}{*}{ Rhizome } & $79-$ & R-DB-CH \\
\hline & & & & & $80-$ & R-DB-Hx \\
\hline & & & & & $81-$ & R-DB-DE \\
\hline & & & & & $82-$ & R-DB-EA \\
\hline & & & & & 83- & R-DB-MI \\
\hline & & & & & 84 & R-DB-Wtr \\
\hline \multirow[t]{3}{*}{14} & \multirow[t]{6}{*}{ Foxglove } & \multirow[t]{6}{*}{ Digitalis lanata } & \multirow{6}{*}{$\begin{array}{l}\text { Botanical } \\
\text { Garden } \\
\text { Nursery }\end{array}$} & \multirow[t]{6}{*}{ Seed } & 85- & S-DL-CH \\
\hline & & & & & $86-$ & S-DL-Hx \\
\hline & & & & & 87- & S-DL-DE \\
\hline & & & & & 88- & S-DL-EA \\
\hline & & & & & 89- & S-DL-MI \\
\hline & & & & & 90 & S-DL-Wtr \\
\hline \multirow[t]{3}{*}{15} & \multirow{6}{*}{$\begin{array}{l}\text { Himalayan } \\
\text { teasel/ } \\
\text { Wopalhaakh }\end{array}$} & \multirow[t]{6}{*}{ Dipsacus inermis } & \multirow{6}{*}{$\begin{array}{l}\text { Faculty of } \\
\text { Forestry, } \\
\text { SKUAST-K }\end{array}$} & \multirow[t]{6}{*}{ Leaves } & 91- & L-DI-CH \\
\hline & & & & & $92-$ & L-DI-Hx \\
\hline & & & & & 93- & L-DI-DE \\
\hline & & & & & 94 & L-DI-EA \\
\hline & & & & & 95- & L-DI-Ml \\
\hline & & & & & $96-$ & L-DI-Wtr \\
\hline \multirow[t]{6}{*}{16} & \multirow{6}{*}{$\begin{array}{l}\text { Wopal } \\
\text { Haakh }\end{array}$} & \multirow{6}{*}{ Dipsacus mitis } & \multirow{6}{*}{$\begin{array}{l}\text { Dachigam } \\
\text { National } \\
\text { Sanctuary }\end{array}$} & \multirow[t]{6}{*}{ Leaves } & 97- & L-DM-CH \\
\hline & & & & & 98- & L-DM-Hx \\
\hline & & & & & 99 & L-DM-DE \\
\hline & & & & & $100-$ & L - DM-EA \\
\hline & & & & & $101-$ & L-DM-Ml \\
\hline & & & & & 102 & L-DM-Wtr \\
\hline \multirow[t]{6}{*}{17} & \multirow{6}{*}{$\begin{array}{l}\text { Maidenhair } \\
\text { tree }\end{array}$} & \multirow[t]{6}{*}{ Gingko biloba } & \multirow{6}{*}{$\begin{array}{l}\text { SKUAST-K., } \\
\text { Shalimar }\end{array}$} & Leaves & $103-$ & L-GB-CH \\
\hline & & & & & 104 & L-GB-Hx \\
\hline & & & & & $105-$ & L-GB-DE \\
\hline & & & & & 106 & L-GB-EA \\
\hline & & & & & $107-$ & L-GB-MI \\
\hline & & & & & $108-$ & L-GB-Wtr \\
\hline 18 & Mulethi & Glycyrrhiza glabra & Brakpora, & Rhizome & 109 & R-GG-CH \\
\hline & & & Anantnag & & 110 & R-GG-Hx \\
\hline & & & & & $111-$ & R-GG-DE \\
\hline & & & & & 112 & R-GG-EA \\
\hline & & & & & $113-$ & R-GG-Ml \\
\hline & & & & & 114 & R-GG-Wtr \\
\hline 19 & Fig & Ficus carica & Buchpora, & Fruit & $115-$ & F-FC-CH \\
\hline & & & Srinagar & & $116-$ & F-FC-Hx \\
\hline & & & & & $117-$ & F-FC-DE \\
\hline & & & & & $118-$ & F-FC-EA \\
\hline & & & & & 119 & F-FC-MI \\
\hline & & & & & 120 & F-FC-Wtr \\
\hline 20 & China rose & Hibiscus & SKIMS Soura, & Petals & $121-$ & P-HR-CH \\
\hline & & & & & $122-$ & P-HR-Hx \\
\hline
\end{tabular}




\begin{tabular}{|c|c|c|c|c|c|c|}
\hline & & sinensis & Srinagar & & $123-$ & P-HR-DE \\
\hline & & & & & 124 & P-HR-EA \\
\hline & & & & & $125-$ & P-HR-MI \\
\hline & & & & & $126-$ & P-HR-Wtr \\
\hline \multirow[t]{6}{*}{21} & \multirow{6}{*}{$\begin{array}{l}\text { Seabuckthor } \\
\text { n/ Badriphal }\end{array}$} & \multirow{6}{*}{$\begin{array}{l}\text { Hippophae } \\
\text { rhamnoides }\end{array}$} & \multirow[t]{6}{*}{ Ladakh } & \multirow[t]{6}{*}{ Leaves } & $127-$ & L-HR-CH \\
\hline & & & & & $128-$ & L-HR-Hx \\
\hline & & & & & $129-$ & L-HR-DE \\
\hline & & & & & $130-$ & L-HR-EA \\
\hline & & & & & $131-$ & L-HR-Ml \\
\hline & & & & & $132-$ & L-HR-Wtr \\
\hline \multirow[t]{6}{*}{22} & \multirow{6}{*}{$\begin{array}{l}\text { Bazar bang / } \\
\text { Ajwain }\end{array}$} & \multirow{6}{*}{ Hyosyamus niger } & \multirow{6}{*}{$\begin{array}{l}\text { Gawkadal, } \\
\text { Srinagar }\end{array}$} & \multirow[t]{6}{*}{ Seeds } & $133-$ & S-HN-CH \\
\hline & & & & & 134 & S-HN-Hx \\
\hline & & & & & 135 & S-HN-DE \\
\hline & & & & & $136-$ & S-HN-EA \\
\hline & & & & & $137-$ & S-HN-Ml \\
\hline & & & & & 138 & S-HN-Wtr \\
\hline \multirow[t]{6}{*}{23} & \multirow[t]{6}{*}{ Bottlegourd } & \multirow[t]{6}{*}{ Lagenaria siceraria } & \multirow{6}{*}{$\begin{array}{l}\text { Buchpora, } \\
\text { Srinagar }\end{array}$} & \multirow[t]{6}{*}{ Seeds } & 139 & S-LS-CH \\
\hline & & & & & $140-$ & S-LS-Hx \\
\hline & & & & & $141-$ & S-LS-DE \\
\hline & & & & & $142-$ & S-LS-EA \\
\hline & & & & & $143-$ & S-LS-MI \\
\hline & & & & & 144 & S-LS-Wtr \\
\hline \multirow[t]{12}{*}{24} & \multirow[t]{12}{*}{ Poppy } & \multirow{12}{*}{$\begin{array}{l}\text { Papaver } \\
\text { somniferum }\end{array}$} & \multirow{12}{*}{$\begin{array}{l}\text { SKUAST-K, } \\
\text { Wadura }\end{array}$} & \multirow{12}{*}{$\begin{array}{l}\text { Flower/Leav } \\
\text { es }\end{array}$} & $145-$ & F-PS-CH \\
\hline & & & & & $146-$ & F-PS-Hx \\
\hline & & & & & $147-$ & F-PS-DE \\
\hline & & & & & 148 & F-PS-EA \\
\hline & & & & & 149 & F-PS-MI \\
\hline & & & & & $150-$ & F-PS-Wtr \\
\hline & & & & & $151-$ & L-PS-CH \\
\hline & & & & & $152-$ & L-PS-Hx \\
\hline & & & & & $153-$ & L-PS-DE \\
\hline & & & & & 154 & L-PS-EA \\
\hline & & & & & 155 & L-PS-MI \\
\hline & & & & & $156-$ & L-PS-Wtr \\
\hline \multirow[t]{6}{*}{25} & \multirow{6}{*}{$\begin{array}{l}\text { Mint/ } \\
\text { Pudina }\end{array}$} & \multirow[t]{6}{*}{ Mentha longifolia } & \multirow{6}{*}{$\begin{array}{l}\text { Buchpora, } \\
\text { Srinagar }\end{array}$} & Leaves & $157-$ & L-ML-CH \\
\hline & & & & & 158 & L-ML-Hx \\
\hline & & & & & 159 & L-ML-DE \\
\hline & & & & & 160 & L-ML-EA \\
\hline & & & & & $161-$ & L-ML-Ml \\
\hline & & & & & 162 & L-ML-Wtr \\
\hline 26 & Mint/ & Mentha arvensis & Botanical & Leaves & 163 & L-MA-CH \\
\hline & Pudina & & Garden & & 164 & L-MA-Hx \\
\hline & & & Nursery & & 165 & L-MA-DE \\
\hline & & & & & 166 & L-MA-EA \\
\hline
\end{tabular}




\begin{tabular}{|c|c|c|c|c|c|c|}
\hline & & & & & $167-$ & L-MA-MI \\
\hline & & & & & 168 & L-MA-Wtr \\
\hline \multirow[t]{6}{*}{27} & \multirow[t]{6}{*}{ Lemonbalm } & \multirow[t]{6}{*}{ Melissa offiinalis } & \multirow{6}{*}{$\begin{array}{l}\text { Botanical } \\
\text { Garden } \\
\text { Nursery }\end{array}$} & \multirow[t]{6}{*}{ Leaves } & 169 & L-MOCH \\
\hline & & & & & 170 & L-MO-Hx \\
\hline & & & & & 171- & L-MO-DE \\
\hline & & & & & $172-$ & L-MO-EA \\
\hline & & & & & $173-$ & L-MO-MI \\
\hline & & & & & 174 & L-MO-Wtr \\
\hline \multirow[t]{6}{*}{28} & \multirow[t]{6}{*}{ Morchella } & \multirow{6}{*}{$\begin{array}{l}\text { Morchella } \\
\text { esculenta }\end{array}$} & \multirow{6}{*}{$\begin{array}{l}\text { Faculty of } \\
\text { Forestry, } \\
\text { SKUAST-K }\end{array}$} & \multirow{6}{*}{ Fruit } & $175-$ & F-ME-CH \\
\hline & & & & & $176-$ & F-ME-Hx \\
\hline & & & & & $177-$ & F-ME-DE \\
\hline & & & & & 178 & F-ME-EA \\
\hline & & & & & 179 & F-ME-Ml \\
\hline & & & & & $180-$ & F-ME-Wtr \\
\hline \multirow[t]{6}{*}{29} & \multirow{6}{*}{$\begin{array}{l}\text { Mulberry/ } \\
\text { Tul }\end{array}$} & \multirow[t]{6}{*}{ Morus alba } & \multirow{6}{*}{$\begin{array}{l}\text { SKUAST-K, } \\
\text { Shalimar }\end{array}$} & \multirow[t]{6}{*}{ Fruit } & $181-$ & F-MA-CH \\
\hline & & & & & $182-$ & F-MA-Hx \\
\hline & & & & & $183-$ & F-MA-DE \\
\hline & & & & & 184 & F-MA-EA \\
\hline & & & & & $185-$ & F-MA-Ml \\
\hline & & & & & $186-$ & F-MA-Wtr \\
\hline \multirow[t]{12}{*}{30} & \multirow{12}{*}{$\begin{array}{l}\text { Buttonweed/ } \\
\text { Sochal }\end{array}$} & \multirow[t]{12}{*}{ Malva sylvestris } & \multirow{12}{*}{$\begin{array}{l}\text { Buchpora, } \\
\text { Srinagar }\end{array}$} & \multirow{12}{*}{$\begin{array}{l}\text { Leaves/Flow } \\
\text { ers }\end{array}$} & $187-$ & L-MS-CH \\
\hline & & & & & 188 & L-MS-Hx \\
\hline & & & & & 189 & L-MS-DE \\
\hline & & & & & 190 & L-MS-EA \\
\hline & & & & & 191- & L-MS-Ml \\
\hline & & & & & $192-$ & L-MS-Wtr \\
\hline & & & & & $193-$ & F-MS-CH \\
\hline & & & & & 194 & F-MS-Hx \\
\hline & & & & & $195-$ & F-MS-DE \\
\hline & & & & & 196 & F-MS-EA \\
\hline & & & & & $197-$ & F-MS-Ml \\
\hline & & & & & $198-$ & F-MS-Wtr \\
\hline \multirow[t]{6}{*}{31} & \multirow{6}{*}{$\begin{array}{l}\text { Oreganol } \\
\text { Marzanjosh }\end{array}$} & \multirow[t]{6}{*}{ Origanum vulgare } & \multirow{6}{*}{$\begin{array}{l}\text { Botanical } \\
\text { Garden } \\
\text { Nursery }\end{array}$} & Leaves & 199 & L-OV-CH \\
\hline & & & & & $200-$ & L-OV-Hx \\
\hline & & & & & 201- & L-OV-DE \\
\hline & & & & & $202-$ & L-OV-EA \\
\hline & & & & & $203-$ & L-OV-Ml \\
\hline & & & & & 204 & L-OV-Wtr \\
\hline 32 & Picroliv/ & Picrorhiza kurroa & Botanical & Leaves & $205-$ & L-PK-CH \\
\hline & Kutki & & Garden & & $206-$ & L-PK-Hx \\
\hline & & & Nursery & & $207-$ & L-PK-DE \\
\hline & & & & & $208-$ & L-PK-EA \\
\hline & & & & & 209 & L-PK-Ml \\
\hline
\end{tabular}




\begin{tabular}{|c|c|c|c|c|c|c|}
\hline & & & & & 210 & L-PK-Wtr \\
\hline \multirow[t]{18}{*}{33} & \multirow{18}{*}{$\begin{array}{l}\text { Himalayan } \\
\text { mayapplel } \\
\text { Bankakril } \\
\text { Wanwangun }\end{array}$} & \multirow{18}{*}{$\begin{array}{l}\text { Podophyllum } \\
\text { hexandrum }\end{array}$} & \multirow[t]{18}{*}{ Gurez } & \multirow{18}{*}{$\begin{array}{l}\text { Fruit/Leaves } \\
\text { /Root }\end{array}$} & 211- & L-PH-CH \\
\hline & & & & & $212-$ & L-PH-Hx \\
\hline & & & & & $213-$ & L-PH-DE \\
\hline & & & & & 214 & L-PH-EA \\
\hline & & & & & $215-$ & L-PH-MI \\
\hline & & & & & 216 & L-PH-Wtr \\
\hline & & & & & $217-$ & F-PH-CH \\
\hline & & & & & $218-$ & F-PH-Hx \\
\hline & & & & & 219 & F-PH-DE \\
\hline & & & & & $220-$ & F-PH-EA \\
\hline & & & & & $221-$ & F-PH-Ml \\
\hline & & & & & $222-$ & F-PH-Wtr \\
\hline & & & & & $223-$ & R-PH-CH \\
\hline & & & & & 224 & R-PH-Hx \\
\hline & & & & & $225-$ & R-PH-DE \\
\hline & & & & & $226-$ & R-PH-EA \\
\hline & & & & & $227-$ & R-PH-Ml \\
\hline & & & & & $228-$ & R-PH-Wtr \\
\hline \multirow[t]{6}{*}{34} & \multirow{6}{*}{$\begin{array}{l}\text { Self-heal } \\
\text { Kalaveoth }\end{array}$} & \multirow[t]{6}{*}{ Prunella vulgaris } & \multirow{6}{*}{$\begin{array}{l}\text { Faculty of } \\
\text { Forestry, } \\
\text { SKUAST-K }\end{array}$} & \multirow{6}{*}{ Leaves } & 229 & L-PV-CH \\
\hline & & & & & $230-$ & L-PV-Hx \\
\hline & & & & & 231- & L-PV-DE \\
\hline & & & & & $232-$ & L-PV-EA \\
\hline & & & & & 233- & L-PV-MI \\
\hline & & & & & 234 & L-PV-Wtr \\
\hline \multirow[t]{12}{*}{35} & \multirow[t]{12}{*}{ Apricot } & \multirow[t]{12}{*}{ Prunus armeniaca } & \multirow[t]{12}{*}{ Leh, Ladakh } & \multirow{12}{*}{$\begin{array}{l}\text { Fruit/ } \\
\text { Leaves }\end{array}$} & $235-$ & L-PA-CH \\
\hline & & & & & $236-$ & L-PA-Hx \\
\hline & & & & & $237-$ & L-PA-DE \\
\hline & & & & & 238 & L-PA-EA \\
\hline & & & & & $239-$ & L-PA-Ml \\
\hline & & & & & $240-$ & L-PA-Wtr \\
\hline & & & & & 241- & F-PA-CH \\
\hline & & & & & $242-$ & F-PA-Hx \\
\hline & & & & & $243-$ & F-PA-DE \\
\hline & & & & & 244 & F-PA-EA \\
\hline & & & & & 245 & F-PA-MI \\
\hline & & & & & 246 & F-PA-Wtr \\
\hline \multirow[t]{6}{*}{36} & \multirow[t]{6}{*}{ Pambchalan } & \multirow[t]{6}{*}{ Rheum emodi } & \multirow{6}{*}{$\begin{array}{l}\text { Faculty of } \\
\text { Forestry, } \\
\text { SKUAST-K }\end{array}$} & \multirow{6}{*}{ Leaves } & 247 & L-RE-CH \\
\hline & & & & & 248 & L-RE-Hx \\
\hline & & & & & 249 & L-RE-DE \\
\hline & & & & & 250 & L-RE-EA \\
\hline & & & & & $251-$ & L-RE-Ml \\
\hline & & & & & 252 & L-RE-Wtr \\
\hline 37 & Rose/ Gulab & Rosa damascene & Dachigam & Petals/ & 253 & P-RD-CH \\
\hline
\end{tabular}




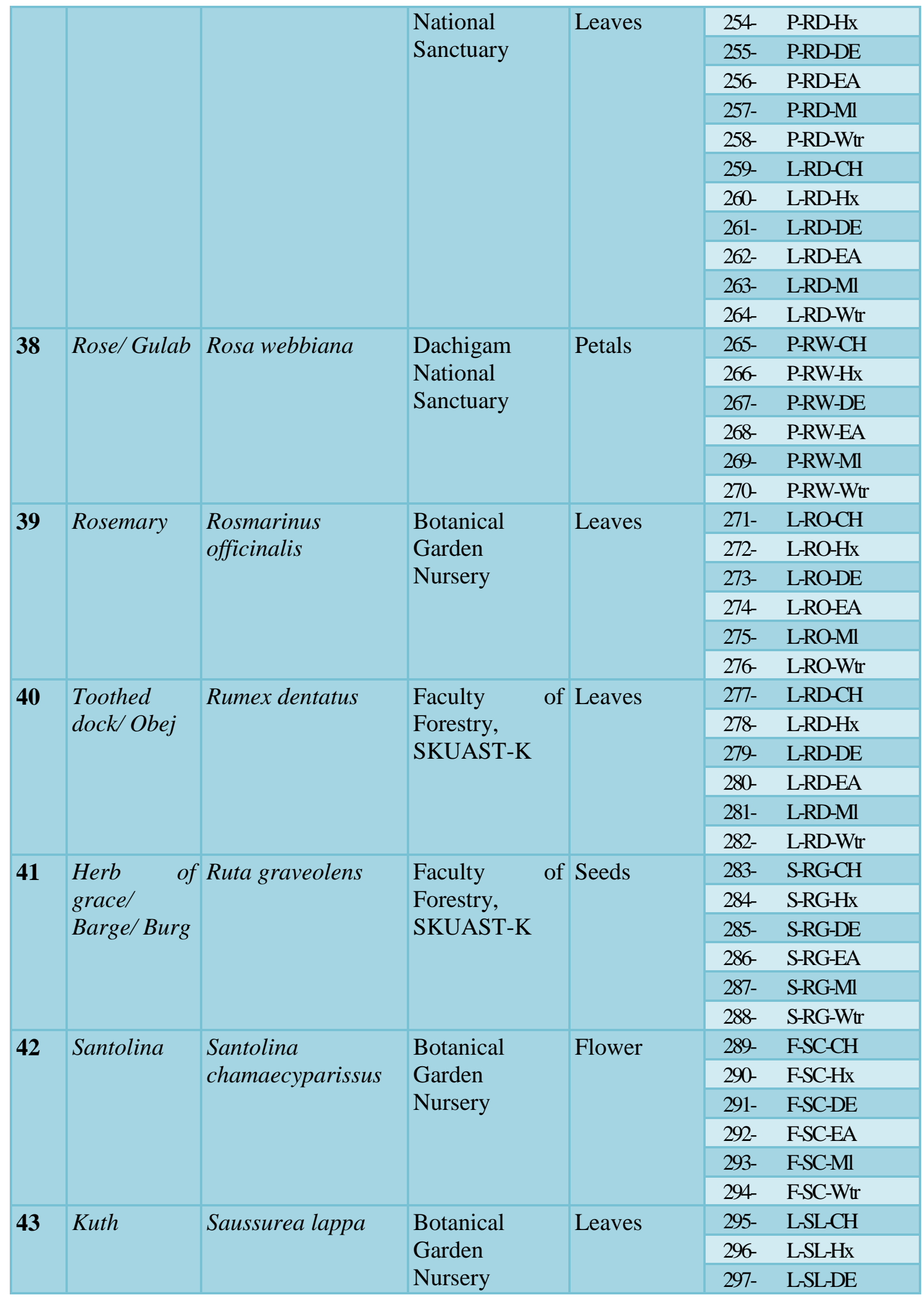




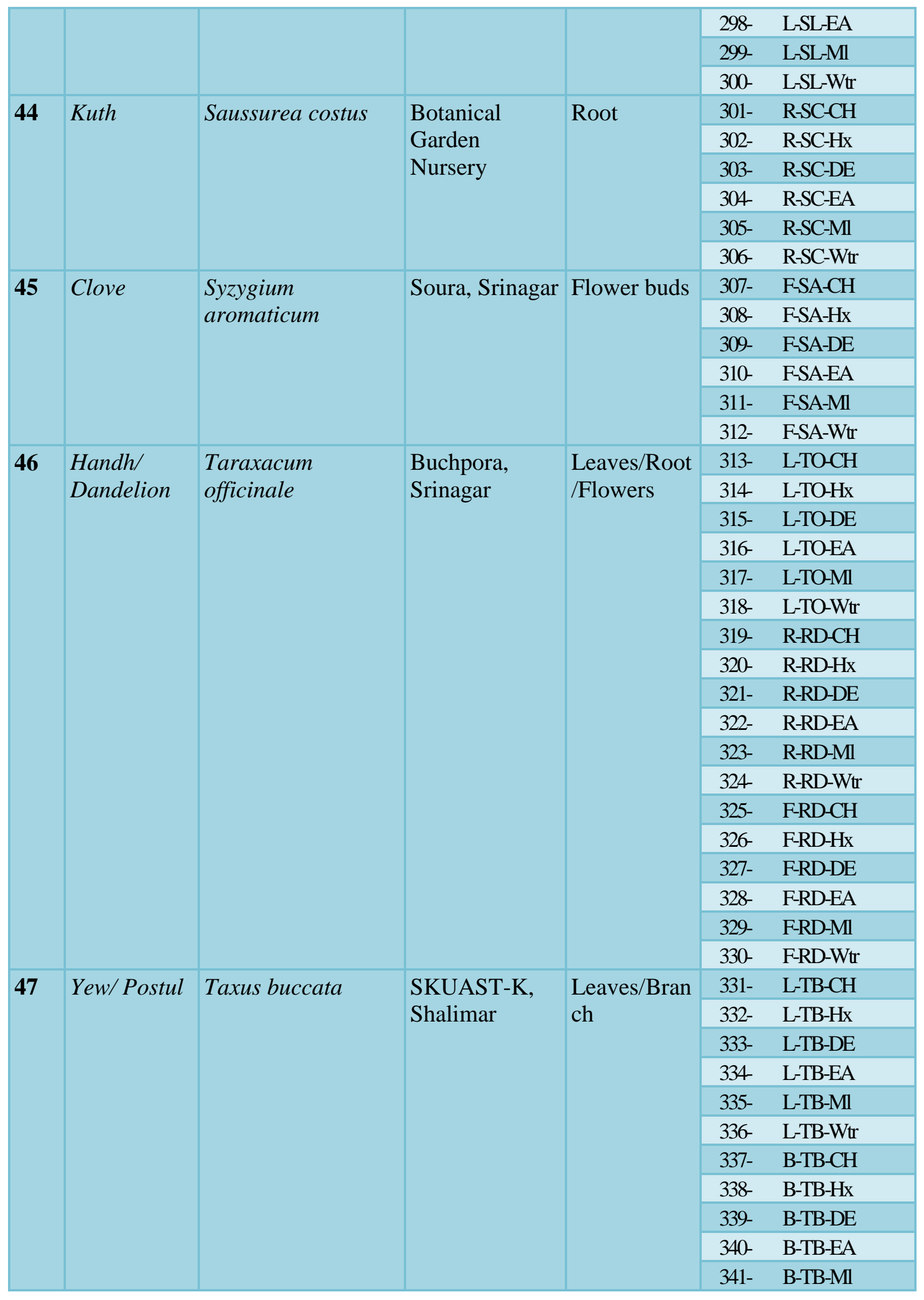




\begin{tabular}{|c|c|c|c|c|c|c|}
\hline & & & & & $342-$ & B-TB-Wtr \\
\hline \multirow[t]{6}{*}{48} & \multirow[t]{6}{*}{ Soi } & \multirow{6}{*}{ Urtica dioca } & \multirow{6}{*}{$\begin{array}{l}\text { Buchpora, } \\
\text { Srinagar }\end{array}$} & \multirow[t]{6}{*}{ Leaves } & $343-$ & L-UD-CH \\
\hline & & & & & 344 & L-UD-Hx \\
\hline & & & & & $345-$ & L-UD-DE \\
\hline & & & & & $346-$ & L-UD-EA \\
\hline & & & & & $347-$ & L-UD-MI \\
\hline & & & & & $348-$ & L-UD-Wtr \\
\hline \multirow[t]{6}{*}{49} & \multirow[t]{6}{*}{ Banafsha } & \multirow[t]{6}{*}{ Viola odorata } & \multirow{6}{*}{$\begin{array}{l}\text { Faculty of } \\
\text { Forestry, } \\
\text { SKUAST-K }\end{array}$} & \multirow{6}{*}{ Leaves } & $349-$ & $\mathrm{L}-\mathrm{VOCH}$ \\
\hline & & & & & $350-$ & L-VO-Hx \\
\hline & & & & & $351-$ & L-VO-DE \\
\hline & & & & & $352-$ & L-VO-EA \\
\hline & & & & & $353-$ & L-VO-Ml \\
\hline & & & & & 354 & L-VO-Wtr \\
\hline \multirow[t]{6}{*}{50} & \multirow[t]{6}{*}{ Banafsha } & \multirow[t]{6}{*}{ Viola biflora } & \multirow{6}{*}{$\begin{array}{l}\text { Faculty of } \\
\text { Forestry, } \\
\text { SKUAST-K }\end{array}$} & \multirow{6}{*}{ Leaves } & $355-$ & $\mathrm{L}-\mathrm{VB}-\mathrm{CH}$ \\
\hline & & & & & $356-$ & L-VB-Hx \\
\hline & & & & & $357-$ & L-VB-DE \\
\hline & & & & & $358-$ & L-VB-EA \\
\hline & & & & & $359-$ & L-VB-Ml \\
\hline & & & & & $360-$ & L-VB-Wtr \\
\hline \multirow[t]{6}{*}{51} & \multirow[t]{6}{*}{ Ginger } & \multirow[t]{6}{*}{ Zingiber officinale } & \multirow{6}{*}{$\begin{array}{l}\text { Buchpora, } \\
\text { Srinagar }\end{array}$} & \multirow[t]{6}{*}{ Rhizome } & $361-$ & R-ZO-CH \\
\hline & & & & & $362-$ & R-ZO-Hx \\
\hline & & & & & $363-$ & R-ZO-DE \\
\hline & & & & & 364 & R-ZO-EA \\
\hline & & & & & $365-$ & R-ZO-Ml \\
\hline & & & & & $366-$ & R-ZO-Wtr \\
\hline \multirow[t]{6}{*}{52} & \multirow{6}{*}{$\begin{array}{l}\text { Shatavaril } \\
\text { Parglas }\end{array}$} & \multirow{6}{*}{$\begin{array}{l}\text { Asparagus } \\
\text { racemosus }\end{array}$} & \multirow{6}{*}{$\begin{array}{l}\text { Botanical } \\
\text { Garden } \\
\text { Nursery }\end{array}$} & \multirow[t]{6}{*}{ Roots } & $367-$ & R-AR-CH \\
\hline & & & & & $368-$ & R-AR-Hx \\
\hline & & & & & $369-$ & R-AR-DE \\
\hline & & & & & $370-$ & R-AR-EA \\
\hline & & & & & $371-$ & R-AR-MI \\
\hline & & & & & $372-$ & R-AR-Wtr \\
\hline
\end{tabular}


Figure.1a Medicinal Plants collected from different regions of Kashmir Valley

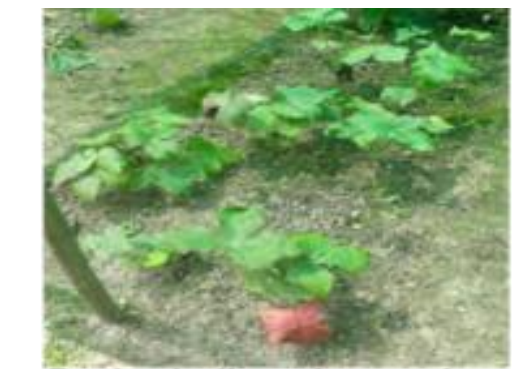

Podophyllum hexandrum

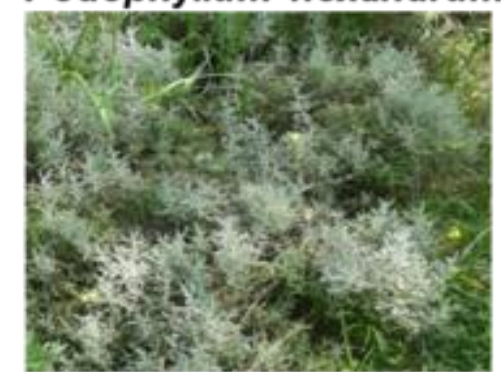

Santolina chamaecyparissus

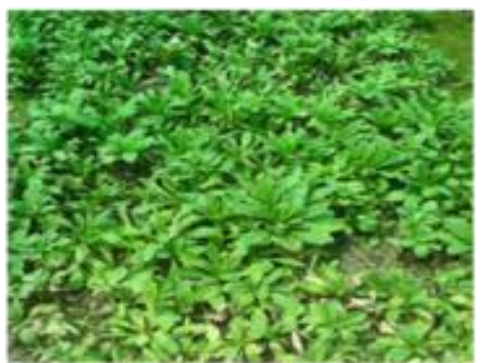

Picrorhiza kurroa

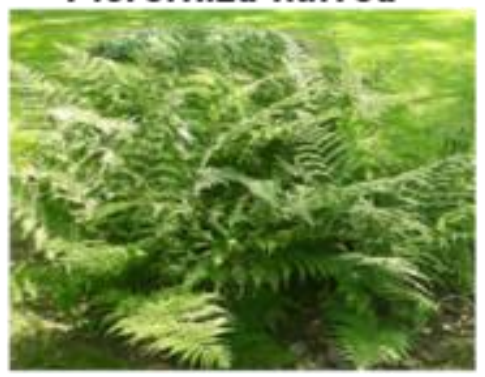

Adiantum venustum

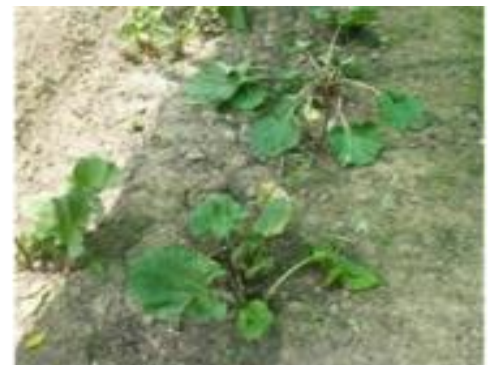

Sassurea lappa

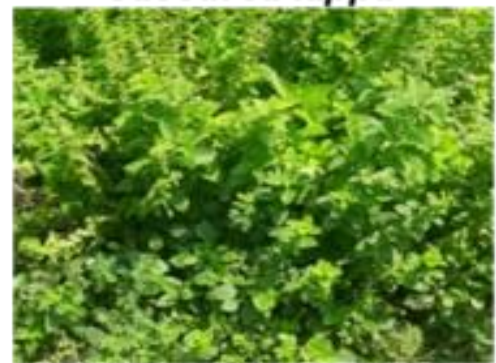

us Melissa officinalis

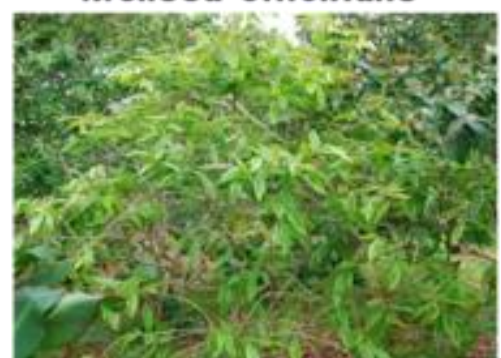

Syzygium aromaticum

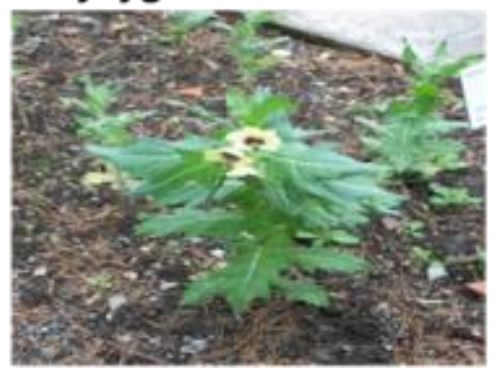

Hyosyamus niger
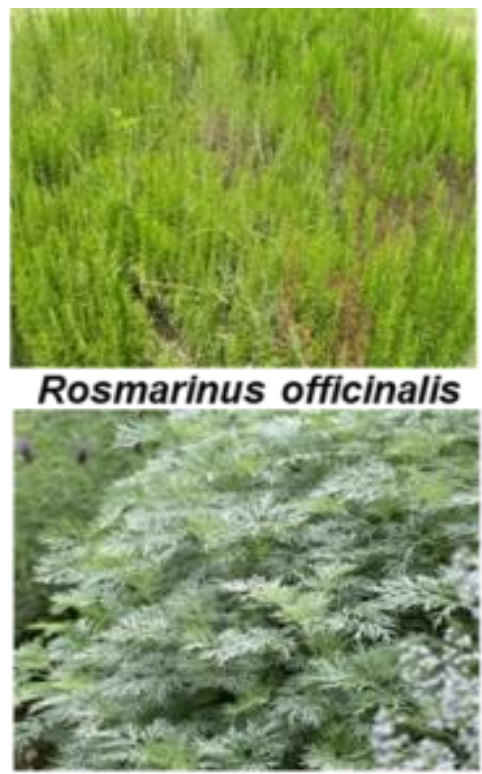

Artemisia absinthum

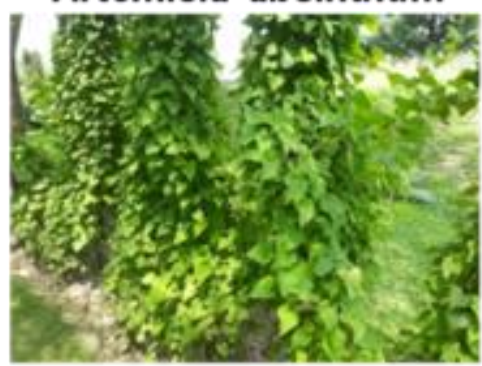

Dioscorea deltoidea

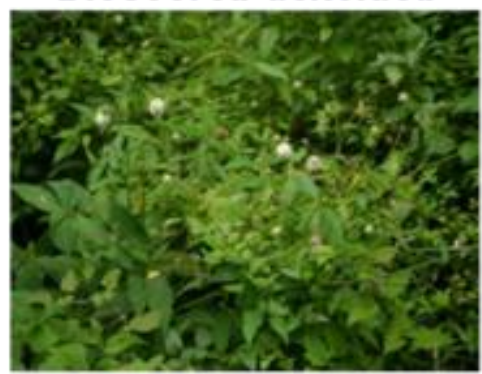

Dipsacus inermis

Figure.1b 
Medicinal Plants collected from different regions of Kashmir Valley
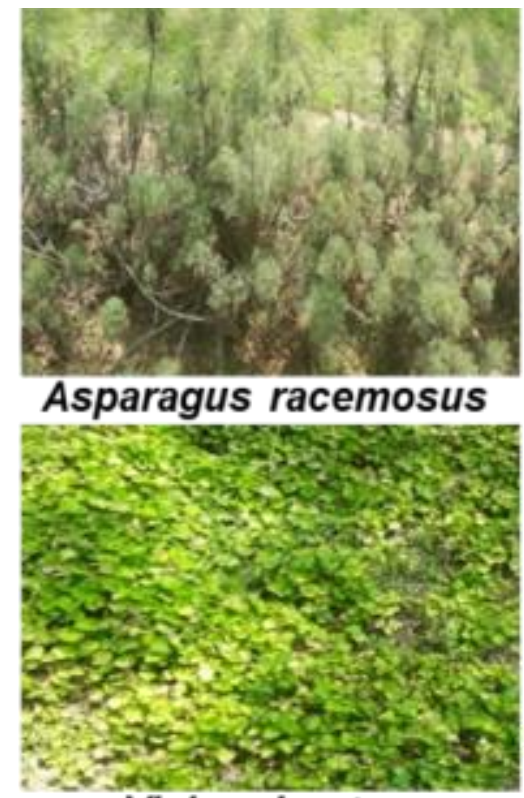

Viola odorata

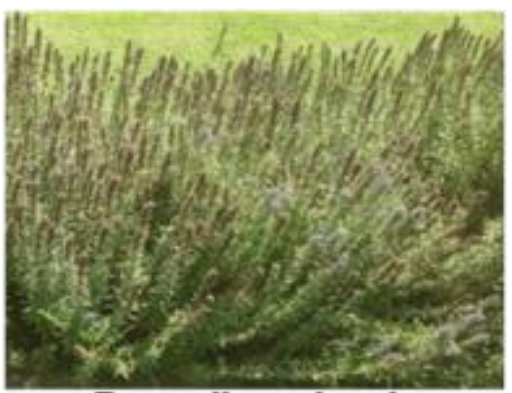

Prunella vulgaris

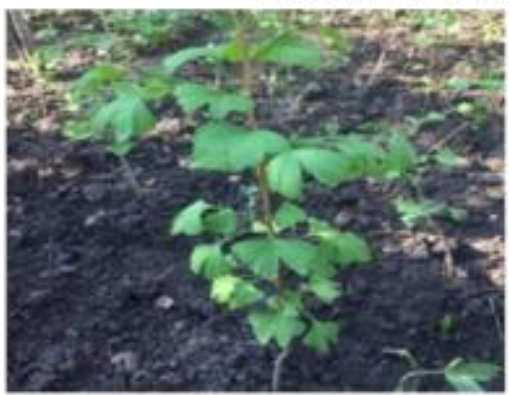

Ginkgo biloba

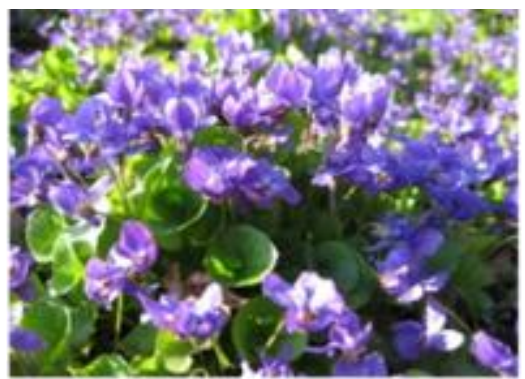

Viola purpurea

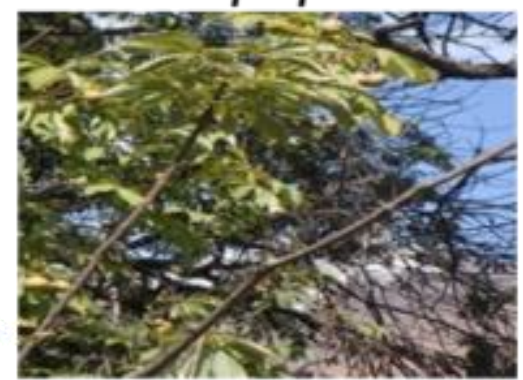

Aesculus indica

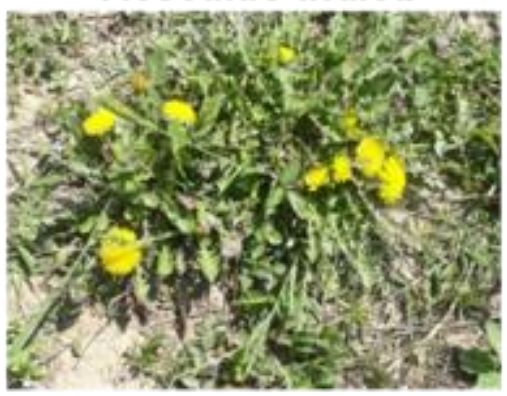

Taraxacum officinale

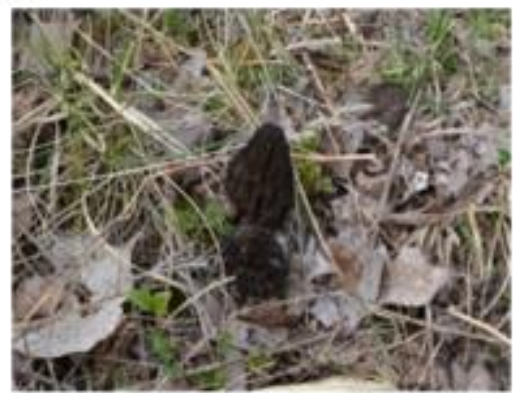

Morchella esculenta

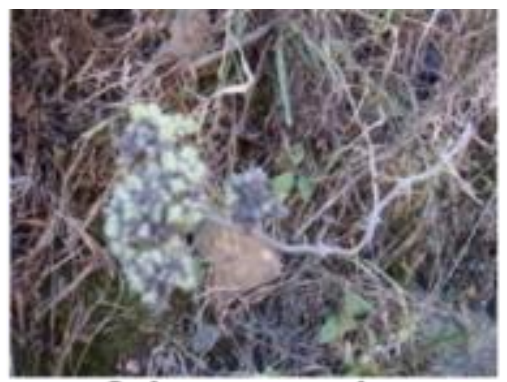

Origanum vulgare

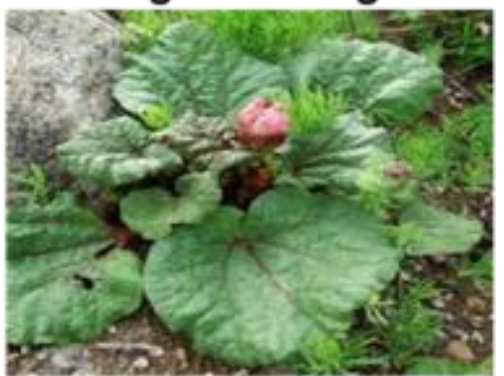

Rheum emodi

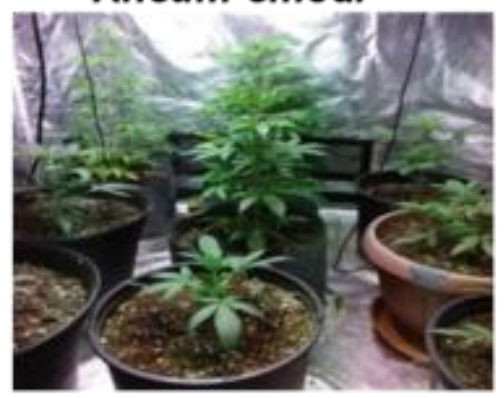

Cannabis sativa

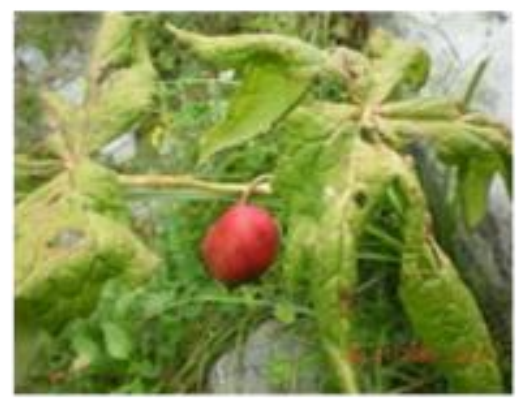

Podophyllum hexandrum 
Figure.1c Medicinal Plants collected from different regions of Kashmir Valley

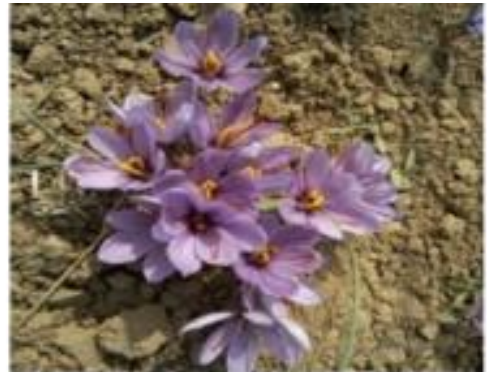

Crocus sativus

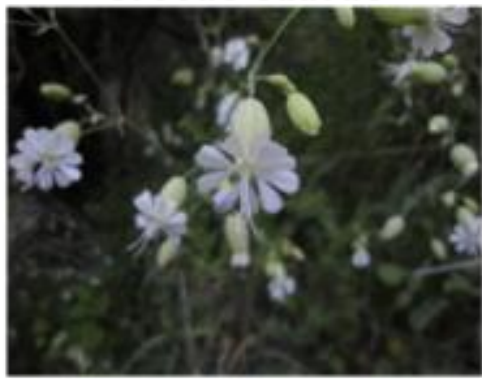

Clerodendrum phlomidis

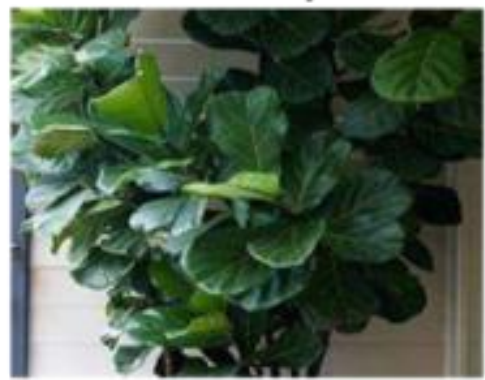

Ficus carica

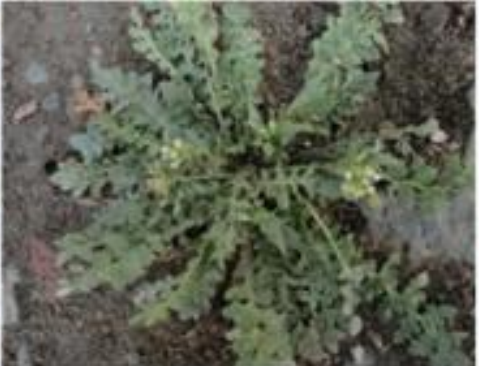

Capsella bursa

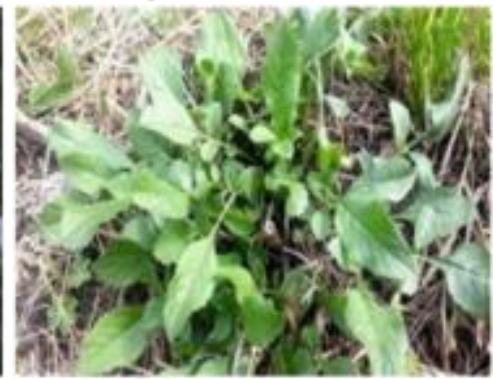

Dipsacus mits

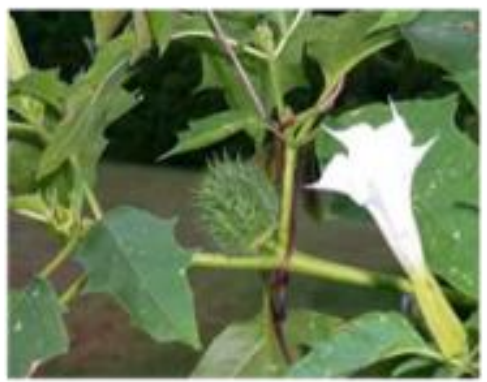

Datura stramonium

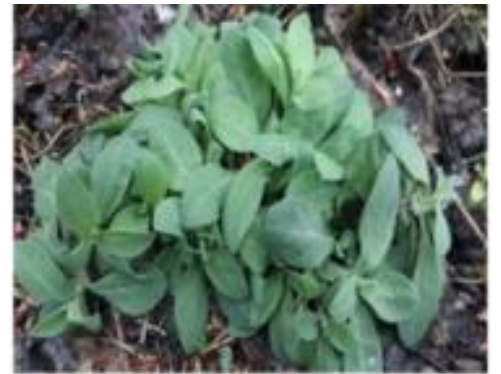

Silene vulgaris

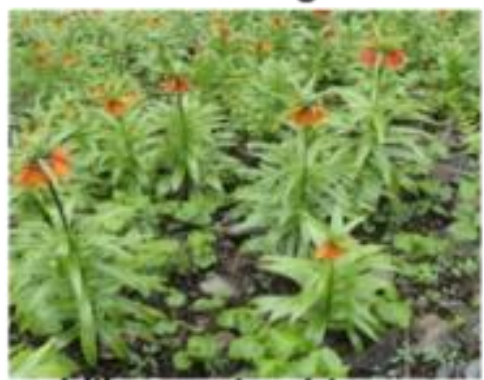

Lilium columbianum

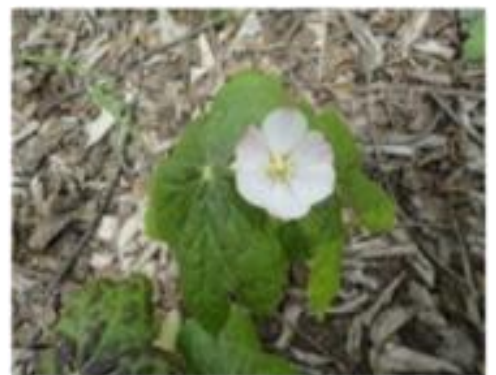

Podophyllum hexandrum 
Figure.1d Medicinal Plants collected from different regions of Kashmir Valley

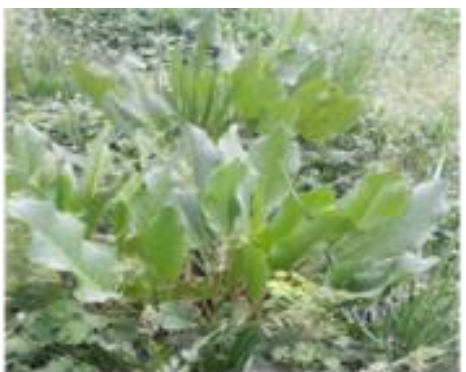

Rumex dentatus

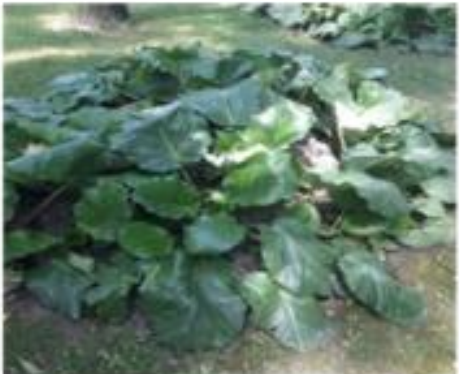

Bergenia ligulata

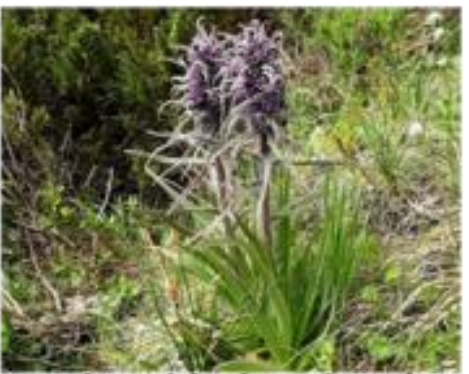

Arnebia benthami

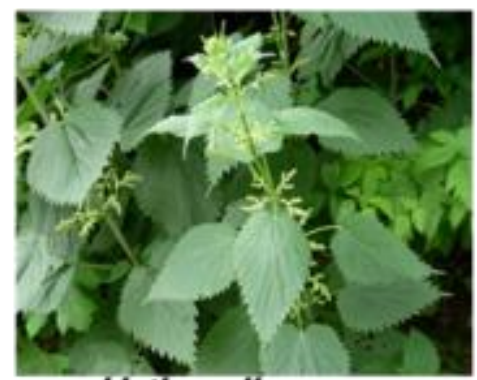

Urtica dioceae

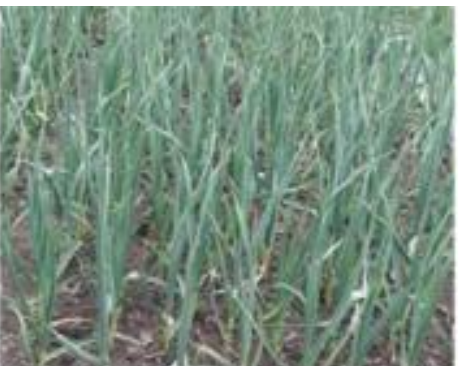

Allium sativum

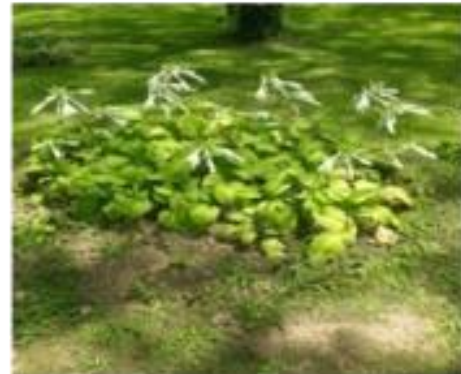

Hosta plantaginea

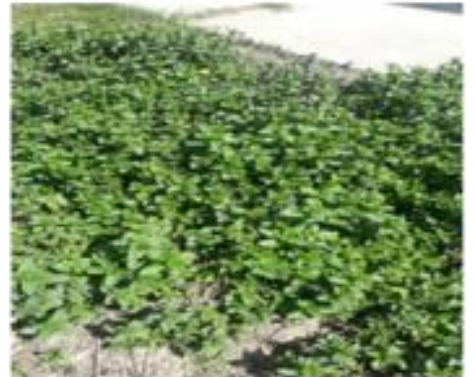

Mentha longifolia

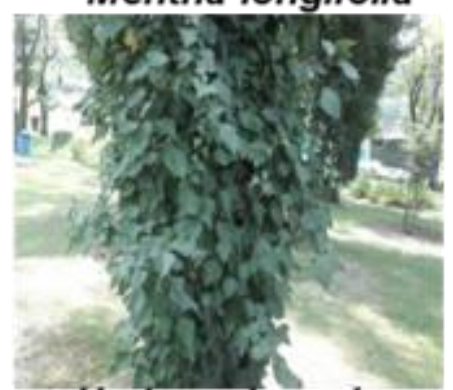

Hedera sinensis

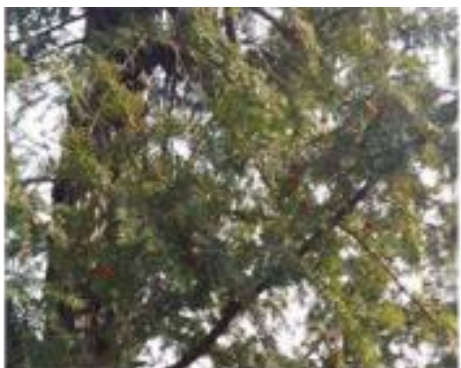

Taxus buccata

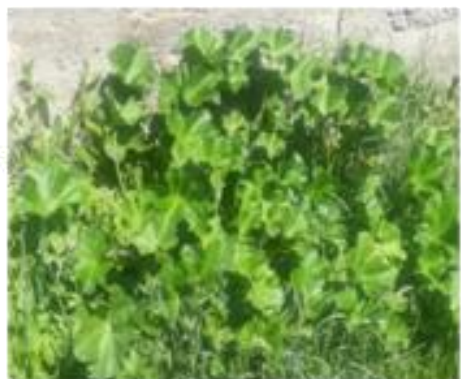

Malva sylvestris

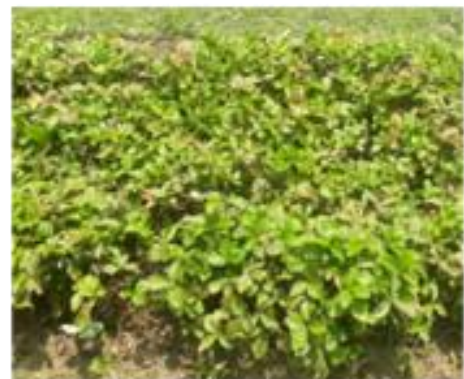

Fragaria ananassa

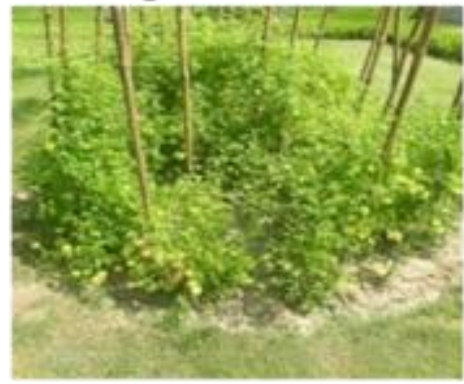

Cardiospermum halicacabum 
Figure.1e Medicinal Plants collected from different regions of Kashmir Valley

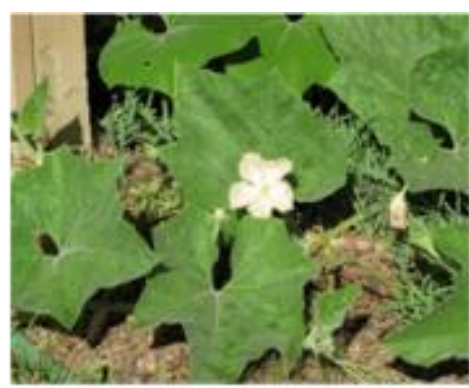

Lagenaria siceraria

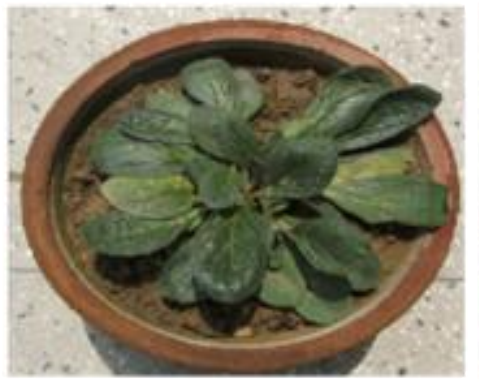

Ajuga bracteosa

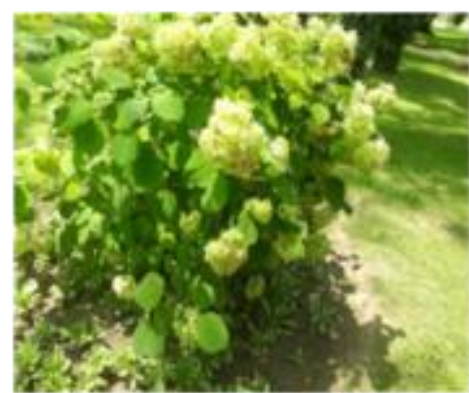

Hydrangea macrophylla

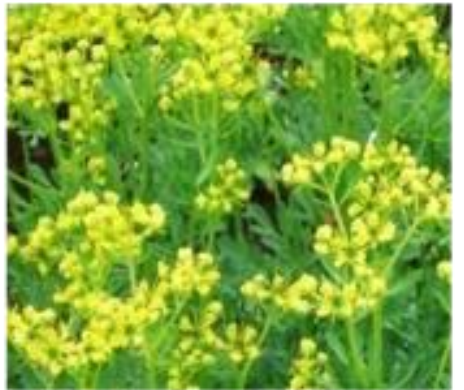

Ruta graveolens

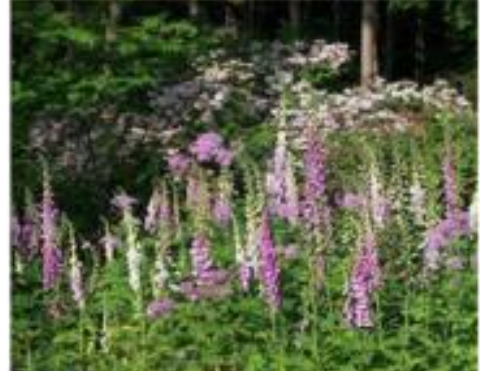

Digitalis lanata

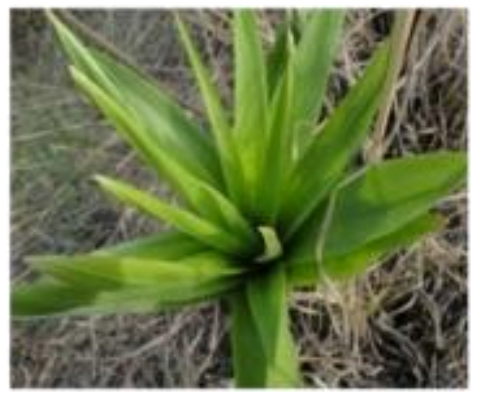

Lilium kashmeriana

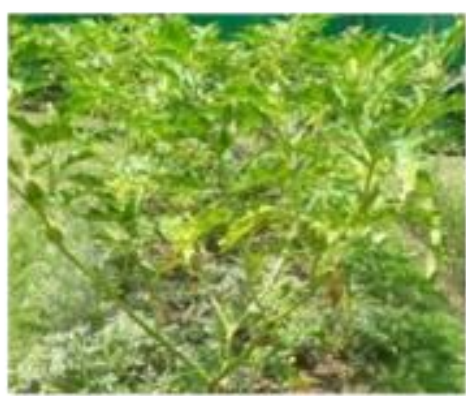

Datura innoxia

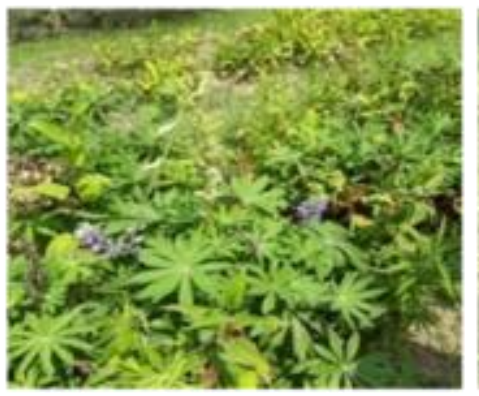

Lupinus micranthus

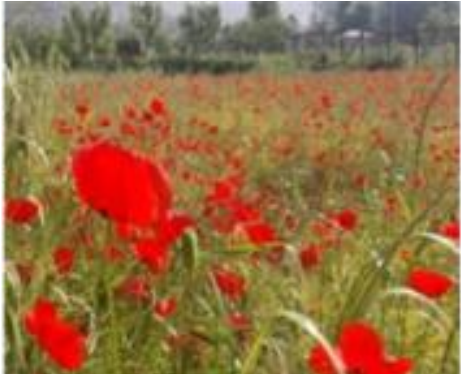

Papaver somniferum

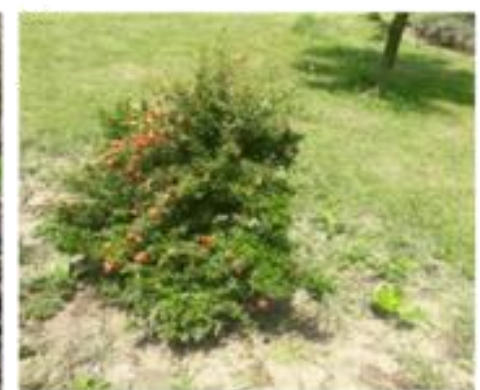

Punica granatum

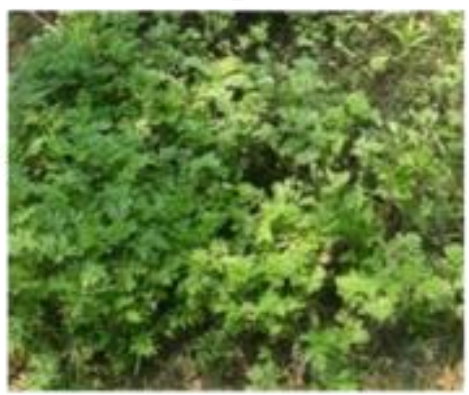

Artemisia annua

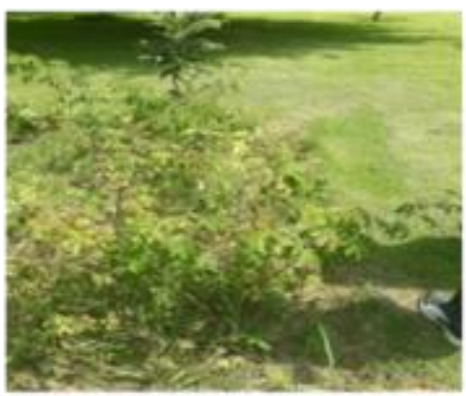

Rosa davurica 
Figure.2 Establishment of Prostate cancer cell lines in RPMI-1640media supplemented with 10\% FBS, 1\% L-Glutamine, 1\% PenStrep and maintained in $5 \% \mathrm{CO}_{2}$ incubator at $37^{\circ} \mathrm{C}$. Representative bright field images at $10 \mathrm{X}$, and $40 \mathrm{X}$ magnifications
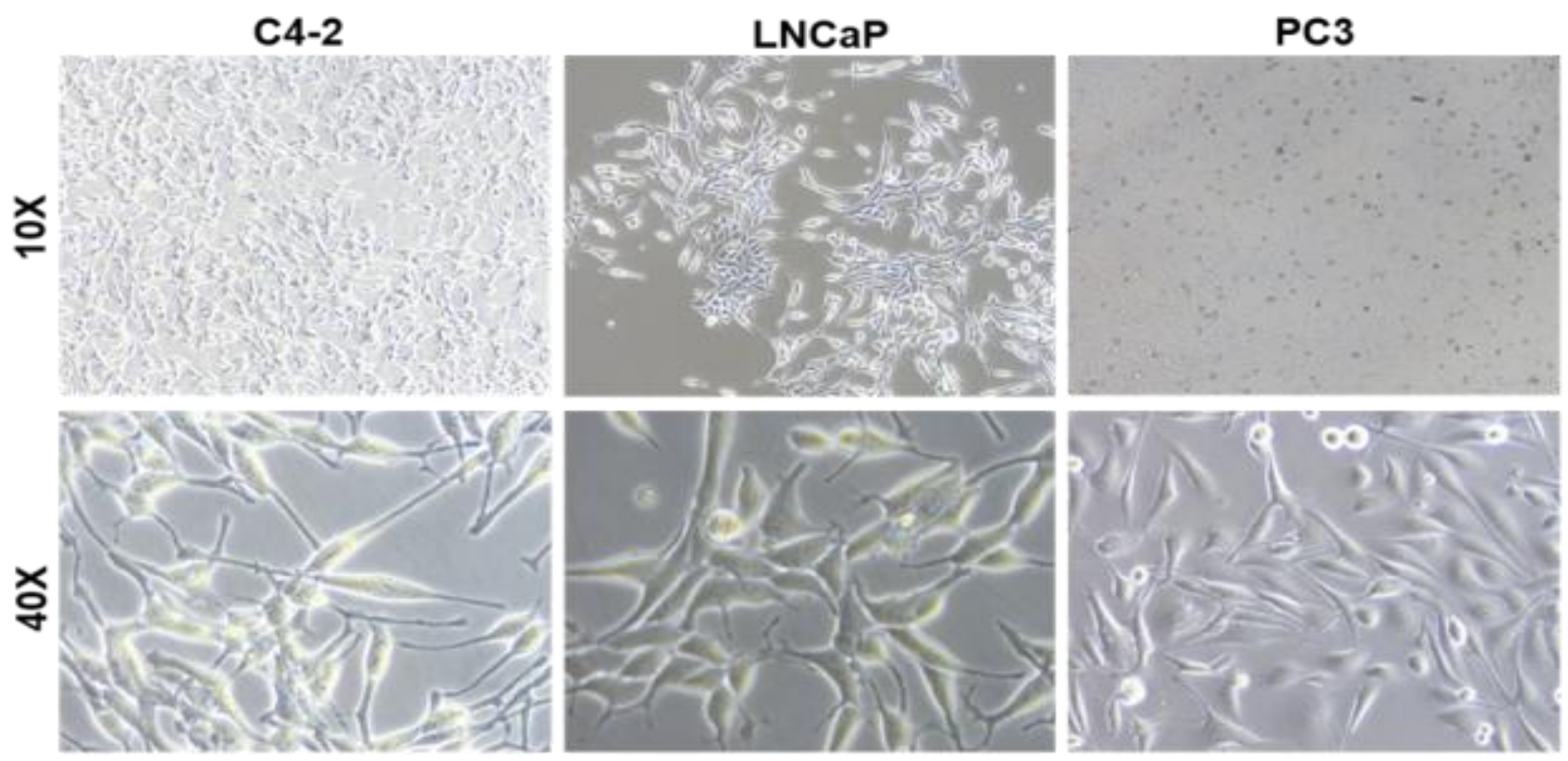

Under MTA with MD Anderson Cancer Centre Texas USA

\section{NCCS, Pune}


Figure.3 Effect of Podophyllum hexandrumon inhibition of CFU in PCa cells.

A.Cells were grown to confluency in RPMI supplemented with $10 \%$ FBS, $1 \%$ L-glutamine,1\% Penstrep and treated with different concentrations of leaf extract of Podophyllum hexandrum. Colonies were counted 7 days after.

B. Quantification of CFU
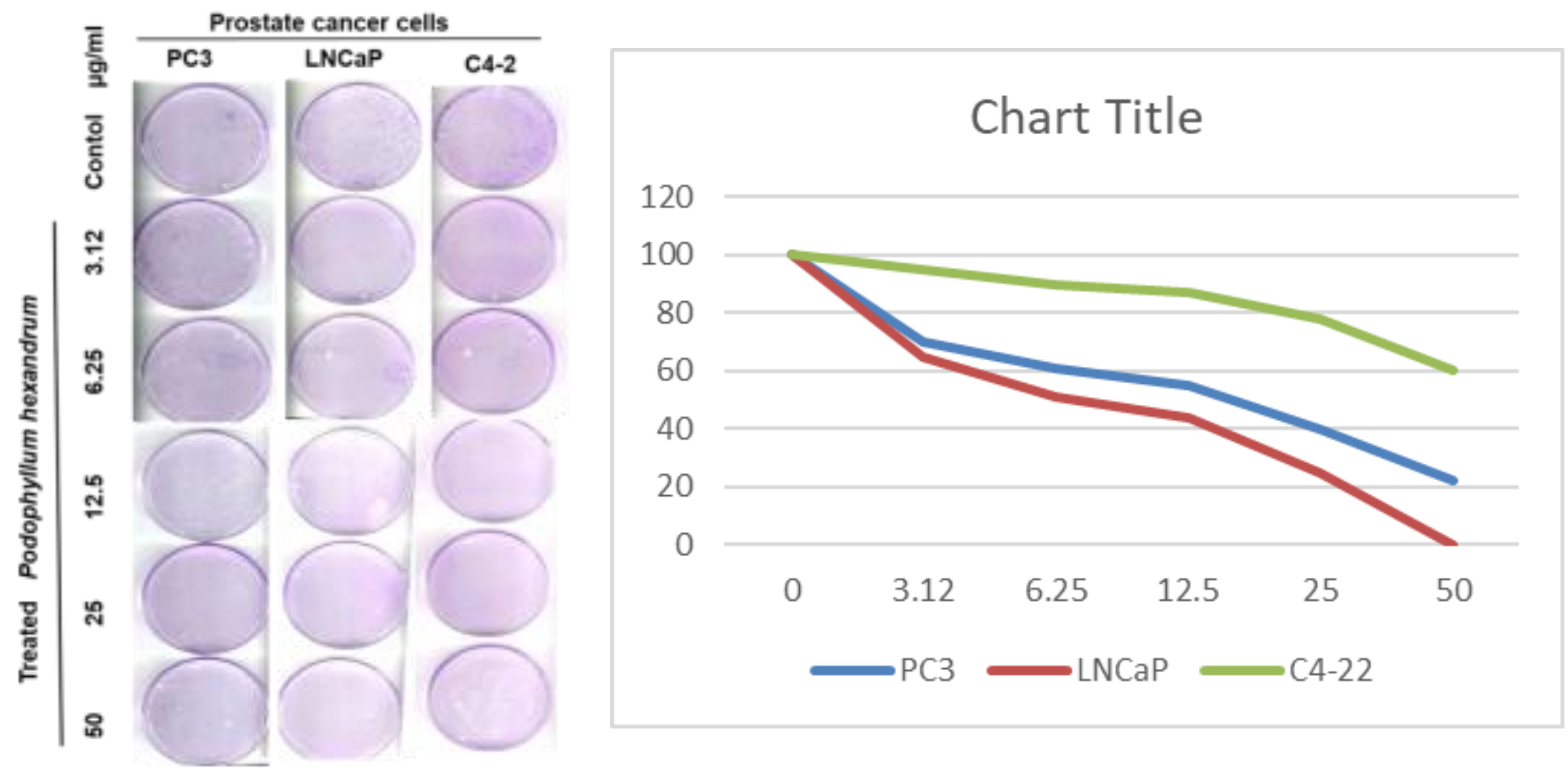
Figure.4 Wound healing assay in C4-2 cells. A. Confluent C4-2 cells were treated with Podophyllum hexandrum extract (50 $\mu$ g/ml) after wounding across the cell monolayer with a sterile pipette tip for $48 \mathrm{hrs}$. Cells were imaged at 0 and 48 hours after treatment and gap widths were measured. There was no significant wound closure after $48 \mathrm{hrs}$ in treated cell lines while there was a near to complete wound closure in untreated cells (control).B. Quantification of gap closure in A

A.

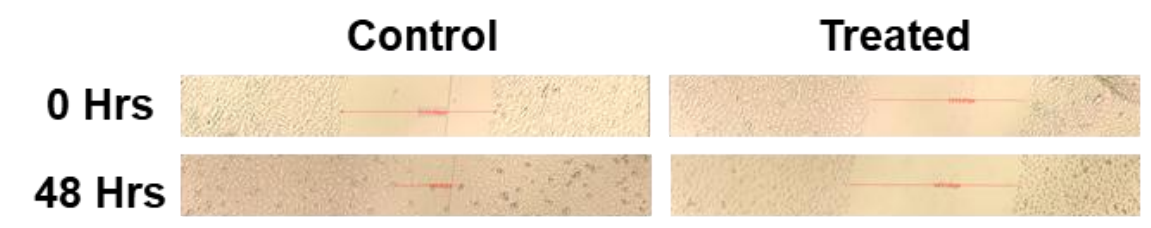

B

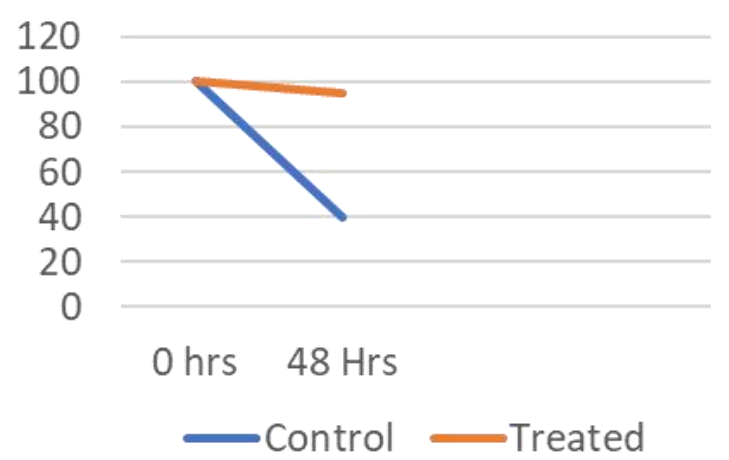


New approaches for identification of novel small-molecule inhibitors of CRPC proliferation are significant in light of the need to overcome resistance of CRPC cells to first- and second-generation antiandrogens such as flutamide, nilutamide, bicalutamide, and the more recently approved enzalutamide. One of best alternatives to these first- and second-generation antiandrogens could be plant based extracts.

In this study, we screened library of 372 plant extracts for their ability to inhibit cancer cell migration and colony forming units in castration resistant prostate cancer cells through wound healing and colony forming unit assays. We identified leaf extract of Podophyllum hexandrum capable of inhibiting CRPC growth and migration. Wound healing assay revealed that in presence of this extract, cancer cells show inhibition of cell movement and no cellular gap closure, thus showing detrimental effect on invasiveness of C4-2 cells. CFU assay depicted inhibition of cellular proliferation by this extract and reduced colony forming units with increasing concentrations in C4-2, $\mathrm{LnCaP}$ and PC3 cells. The examinations herein indicate that plant extracts are novel drugs having the ability to inhibit CRPC proliferation. These results are consistent with those of Masoodi et. al. who observed synthetic molecules inhibited the cancer cell migration in CRPC cells (Dar, Masoodi et al., 2014). Thus, Podophyllum hexandrum leaf extract can be used for developing natural product drugs as potent therapeutics for CRPC because CRPC patients are on synthesized drugs. Therefore, this investigation provides a wonderful starting point for the development of more effective analogs to combat prostate cancer.

In summary, we have generated a screening protocol for plant-based extracts having the ability of reducing proliferation and cell movement in CRPC cells. Identification of leaf extract of Podophyllum hexandrumas antiproliferative and anti-invasive extract in CRPC cells was possible through our investigation. Further characterization studies of this extract may lead to new molecules with the capability to treat CRPC patients. Follow up studies on this aspect could focus on the molecular mechanisms of antiproliferation of cancer cells by plant extracts.

\section{References}

Agyare, C., V. Spiegler, et al., (2018). "An ethnopharmacological survey of medicinal plants traditionally used for cancer treatment in the Ashanti region, ghana." Journal of ethnopharmacology 212: 137-152.

Aw-Yong, P. Y., P. H. Gan, et al., (2018). Nanoparticles as carriers of phytochemicals: Recent applications against lung cancer." Int. J. Res. Biomed. Biotechnol 7: 1-11.

Bhat, M. Y., M. Z. Gul, et al., (2018). "An in vitro Study of the Antioxidant and Antiproliferative Properties of Artemisia absinthium-A Potent Medicinal Plant." Free Radicals \& Antioxidants 8(1).

Buyel, J. (2018). "Plants as sources of natural and recombinant anti-cancer agents." Biotechnology advances 36(2): 506520.

Dar, J. A., K. Z. Masoodi, et al., (2014). "The $\mathrm{N}$-terminal domain of the androgen receptor drives its nuclear localization in castration-resistant prostate cancer cells." The Journal of steroid biochemistry and molecular biology 143: 473-480.

Dereli, F. T. G., M. Ilhan, et al., (2019). "New Drug Discovery from Medicinal Plants and Phytoconstituents for Depressive Disorders." CNS \& Neurological 
Disorders-Drug Targets (Formerly Current Drug Targets-CNS \& Neurological Disorders) 18(2): 92-102.

Eisermann, K., J. A. Dar, et al., (2015). Poly (A) binding protein cytoplasmic 1 is a novel co-regulator of the androgen receptor." PLoS ONE 10(7): e0128495.

Isgut, M., M. Rao, et al., (2018). Application of Combination High-Throughput Phenotypic Screening and Target Identification Methods for the Discovery of Natural Product-Based Combination Drugs. Medicinal research reviews 38(2): 504-524.

Jacob, M., X.-C. Li, et al., (2019). Drug Discovery from Complex Mixtures: Serendipity, Screening, and Characterization. The Science and Regulations of Naturally Derived Complex Drugs, Springer: 297-310.

Jamshidi-Kia, F., Z. Lorigooini, et al., (2018). "Medicinal plants: Past history and future perspective." Journal of herbmed pharmacology 7(1).

Jing, Y., M. M. Nguyen, et al., (2018). "DHX15 promotes prostate cancer progression by stimulating Siah2mediated ubiquitination of androgen receptor." Oncogene 37(5): 638.

Johnston, P. A., M. M. Nguyen, et al., (2016). "Development and implementation of a high-throughput high-content screening assay to identify inhibitors of androgen receptor nuclear localization in castration-resistant prostate cancer cells." Assay and drug development technologies 14(4): 226-239.

Kaushik, P. and P. P. D. Kaushik (2018). A comprehensive review on medicinal plants with anticancer activity." Global Journal of Pharmaceutical Education and Research 3(1-2).

Keavey, S. M. and C. W. J. Thompson (2018). Screening for Prostate Cancer in Black Men. Clinician Reviews 28(10): 24-28.
Kebebe, D., Y. Liu, et al., (2018). Tumortargeting delivery of herb-based drugs with cell-penetrating/tumor-targeting peptide-modified nanocarriers." International journal of nanomedicine 13: 1425 .

Khan, T. and P. Gurav (2018). PhytoNanotechnology: Enhancing delivery of plant based anti-cancer drugs. Frontiers in pharmacology 8: 1002.

Li, G. and H. X. Lou (2018). Strategies to diversify natural products for drug discovery. Medicinal research reviews 38(4): 1255-1294.

Masoodi, K. Z., Y. Xu, et al., (2017). Inhibition of androgen receptor nuclear localization and castration-resistant prostate tumor growth by pyrroloimidazole-based small molecules. Molecular cancer therapeutics 16(10): 2120-2129.

Pascal, L. E., K. Z. Masoodi, et al., (2015). $5 \alpha$-Reductase Inhibition Coupled with Short Off Cycles Increases Survival in the LNCaP Xenograft Prostate Tumor Model on Intermittent Androgen Deprivation Therapy. The Journal of urology 193(4): 1388-1393.

Rupani, R. and A. Chavez (2018). Medicinal plants with traditional use: Ethnobotany in the Indian subcontinent. Clinics in dermatology 36(3): 306-309.

Seca, A. and D. Pinto (2018). Plant secondary metabolites as anticancer agents: successes in clinical trials and therapeutic application. International journal of molecular sciences 19(1): 263.

Tewari, D., P. Rawat, et al., (2019). Adverse drug reactions of anticancer drugs derived from natural sources." Food and Chemical Toxicology 123: 522-535.

Ullah, M. and A. Ahmad (2019). Nutraceuticals and Natural Product Derivatives: Disease Prevention \& Drug 
Discovery, Wiley-Blackwell.

Wang, D., M. M. Nguyen, et al., (2015). Splicing factor Prp8 interacts with NESAR and regulates androgen receptor in prostate cancer cells. Molecular endocrinology 29(12): 17311742.
Zhong, M., L. E. Pascal, et al., (2018). Concurrent EAF2 and ELL2 loss phenocopies individual EAF2 or ELL2 loss in prostate cancer cells and murine prostate. American journal of clinical and experimental urology 6(6): 234.

\section{How to cite this article:}

Wasia Showkat, F.A. Nehvi, Zahoor A. Dar, Javeed A. Mugloo, Niyaz A. Dar, Shakeel A. Mir and Ashraf Bhat, M. 2019. Study on Medicinal Plants of Kashmir Valley for Anti-Proliferative, Anti-Invasive Activities against Prostate Cancer. Int.J.Curr.Microbiol.App.Sci. 8(06): 207-230. doi: https://doi.org/10.20546/ijcmas.2019.806.025 